Article

\title{
Thermal History Dependent Al Distribution in Aluminum Substituted Strontium Hexaferrite
}

\author{
Manuel Häßner ${ }^{1}$, Denis A. Vinnik ${ }^{2}$ and Rainer Niewa ${ }^{1, *(\mathbb{D}}$ \\ 1 University of Stuttgart, Pfaffenwaldring 55, 70569 Stuttgart, Germany; manuel.haessner@iac.uni-stuttgart.de \\ 2 South Ural State University, Lenin's Prospect 76, Chelyabinsk 454080, Russia; denisvinnik@gmail.com \\ * Correspondence: rainer.niewa@iac.uni-stuttgart.de; Tel.: +49-711-685-64217
}

Received: 29 January 2020; Accepted: 12 February 2020; Published: 13 February 2020

\begin{abstract}
Single crystals of aluminum substituted strontium hexaferrite $\mathrm{SrFe}_{12-x} \mathrm{Al}_{x} \mathrm{O}_{19}$ were grown from sodium oxide based flux. The substitution level aimed for was $x=1.2$. Annealing experiments performed on single crystals show that the $\mathrm{Al}$ distribution on the five iron sites of the hexaferrite structure depends on the annealing time at $900{ }^{\circ} \mathrm{C}$. Single crystal X-ray diffractometry shows that annealing a crystal after the initial synthesis has an impact on the Al content on the octahedrally and tetrahedrally coordinated sites. Furthermore, it was found that heating in a corundum crucible increases the overall $\mathrm{Al}$ content. Magnetic measurements show that annealing in a platinum or corundum crucible decreases coercivity and remanence while the saturation magnetization is hardly influenced.
\end{abstract}

Keywords: cation distribution; aluminum substituted hexaferrite; magnetic materials

\section{Introduction}

The materials class of ferrites comprises a whole field of oxidic compounds with similar building motifs. They can all be described by stacking certain building blocks, called S, R and T blocks [1]. Although a wide variety of ferrites is known, the best-known ones are certainly the spinel (also called S-type) [2,3] and the barium hexaferrite $\mathrm{BaFe}_{12} \mathrm{O}_{19}$ (called M-type, $\mathrm{BaM}$ ) [4]. The M-type ferrite shines with superior magnetic properties, relatively high Curie temperatures and good chemical stability. These properties grant it several applications in the industry such as in storing components, part of inductors and in microwave devices [5,6] and make the M-type a prominent topic in functional materials research. Several synthesis methods have been described like the classic solid-state synthesis, crystal growth in flux, sol-gel method and hydrothermal approaches to receive the product in bulk, as thin films or even as nanoparticles [7-13]. Many researchers focus on substituting iron, barium or both and the resulting influence on the structure and properties. Substitutions with various isovalent cations have been reported, like strontium(II) and lead(II) for barium(II) [14,15] as well as aluminum(III) and chromium(III) for iron(III) [16,17]. Furthermore, aliovalent substitutions are possible, such as lanthanum(III) [18] on the alkaline earth metal site and copper(II), titanium(IV) or tungsten(VI) for the transition metal [19-21]. The latter kind of substitution can be accomplished in higher degree by co-substitution with ions carrying higher and lower charges than the substituted element. In the case of manganese substitution, three different oxidation states $\mathrm{Mn}(\mathrm{II}), \mathrm{Mn}(\mathrm{III})$ and $\mathrm{Mn}$ (IV) were detected to coexist via X-ray absorption spectroscopy [22].

We have studied $\mathrm{Al}(\mathrm{III})$ substituted strontium hexaferrite, with a special focus on the cation distribution on the mixed sites and resulting magnetic properties. Introducing $\mathrm{Al}(\mathrm{III})$ to the hexaferrite system is reported to increase the coercivity, which is desirable for many applications. Saturation magnetization and remanence decrease concurrently, as aluminum(III) has no unpaired spins as opposed to iron(III) [23]. Using the knowledge accumulated by investigating hexaferrites 
with different substituents and degrees of substitution, the magnetic properties of the material can be fine-tuned to fit its desired use best.

\section{Materials and Methods}

All used chemicals were obtained from the Ural Plant of Chemicals, Russia, with a purity of 99.9\%. Aluminum substituted M-type ferrite $\mathrm{SrFe}_{12-x} \mathrm{Al}_{x} \mathrm{O}_{19}(\mathrm{SrM})$ was prepared from strontium carbonate $\left(\mathrm{SrCO}_{3}\right)$, iron(III) oxide $\left(\gamma-\mathrm{Fe}_{2} \mathrm{O}_{3}\right)$ and aluminum oxide $\left(\gamma-\mathrm{Al}_{2} \mathrm{O}_{3}\right)$ with the molar ratio 1:5.4:0.6. The initial mixture contained 26.3 mol-\% of sodium carbonate $\left(\mathrm{Na}_{2} \mathrm{CO}_{3}\right)$ as flux to enhance crystal growth during the procedure, as Gambino and Leonhard suggested in their work [24]. The powder mixture was homogenized using an agate mortar and then filled into a platinum crucible. The crucible was heated in a resistance furnace, which was equipped with a thermocouple PR-30/6 as well as a precision thermostat RIF-101. For further homogenization in the flux, the mixture was held at $1260{ }^{\circ} \mathrm{C}$ for $3 \mathrm{~h}$ and then cooled to $900{ }^{\circ} \mathrm{C}$ with a cooling rate of $4.5 \mathrm{~K} / \mathrm{h}$. Afterwards, the system was allowed to cool to room temperature naturally.

The synthesis yielded a crystalline product with crystal sizes up to several millimeters. Selected crystals were annealed to examine any cation distribution changes in the structure. A larger crystal was selected and divided in three pieces. One was put in a platinum crucible and one in a corundum crucible and heated to $900{ }^{\circ} \mathrm{C}$. The temperature was held for $20 \mathrm{~h}$ followed by a slow cooling with a rate of $15 \mathrm{~K} / \mathrm{h}$. Various fragments of these crystals were analyzed via single crystal X-ray diffraction (scXRD) and wavelength dispersive X-ray spectroscopy (WDX).

Powder X-ray diffraction was carried out using a STADI-P diffractometer from STOE\&Cie equipped with a Mythen-1K detector and Mo $K_{\alpha}$ radiation $\left(\lambda_{\mathrm{Mo}}=71.073 \mathrm{pm}\right)$. ScXRD was performed on smaller fragments with a four-circle diffractometer $\kappa$-CCD by Bruker-Nonius with monochromatic Mo $K_{\alpha}$ radiation.

The composition and homogeneity of several crystals were further investigated via scanning electron microscopy (SEM) and WDX using a Cameca SX 100. The samples were coated with a thin carbon layer to avoid accumulation of charge. Used standards for the quantification were celestine $\left(\mathrm{SrSO}_{4}\right)$ for strontium, hematite $\left(\mathrm{Fe}_{2} \mathrm{O}_{3}\right)$ for iron and corundum $\left(\mathrm{Al}_{2} \mathrm{O}_{3}\right)$ for aluminum.

Magnetic properties were measured using a MPMS3 SQUID magnetometer from Quantum Design, allowing hysteresis measurements with a magnetic field strength range of $-70 \mathrm{kOe} \leq H \leq 70 \mathrm{kOe}$. The determined properties were coercivity, remanence and saturation magnetization. The powdered sample or selected crystals were either put in plastic capsules and immobilized using cotton wool or fixed on a rotatable sample holder with a special glue.

\section{Results and Discussion}

\subsection{Structure and Composition}

Figure 1 shows a backscattered electron SEM picture of two exemplary crystals of up to about $800 \mu \mathrm{m}$ length. The powder diffraction pattern of the product (black, up), and a simulated diffractogram of unsubstituted strontium hexaferrite $\mathrm{SrFe}_{12} \mathrm{O}_{19}$ ( $\mathrm{SrM}$, red, down [14]) as references, are shown in Figure 2. A comparison of both patterns proves that the described synthesis yields single phase material. It can also be seen that minor $\mathrm{Al}$ substitution hardly affects reflex positions and intensities compared to unsubstituted SrM.

Both the powder pattern and the single crystal data refinement show that an aluminum containing product, like unsubstituted SrM, crystallizes in the magnetoplumbite structure [4,14], space group $P 6_{3} / m m c$ with $a \approx 587 \mathrm{pm}$ and $c \approx 2300 \mathrm{pm}$. The exact lengths of the unit cell axes vary depending on $\mathrm{Al}$ content and annealing time. Crystallographic data, refinement parameters and measurement conditions for three investigated single crystals with different thermal history are summarized in Table 1. Crystal 1 was investigated directly after the synthesis. Crystals 2 and 3 were annealed for $20 \mathrm{~h}$ at $900{ }^{\circ} \mathrm{C}$ in platinum or corundum crucibles, respectively. 


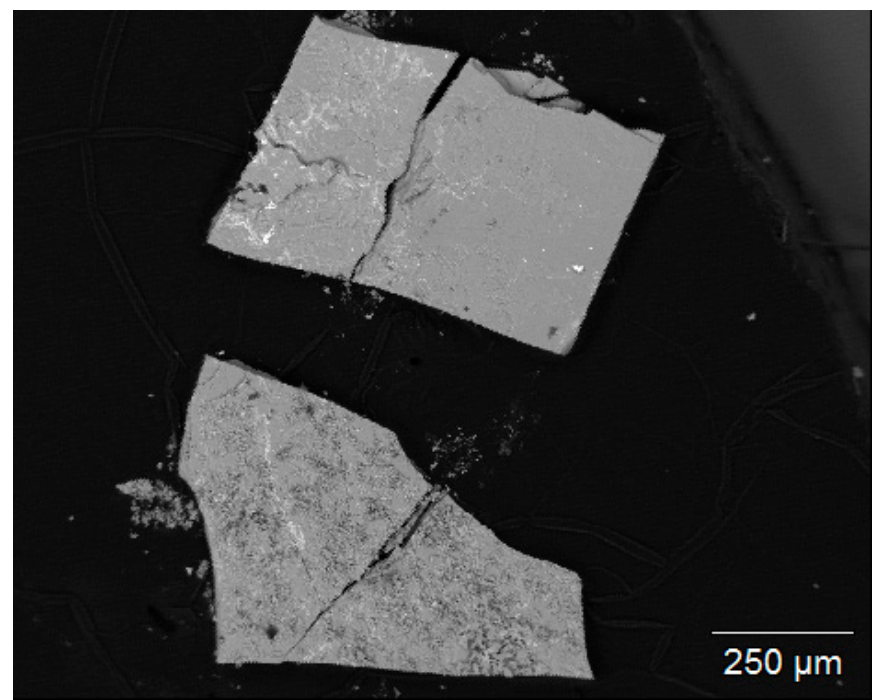

Figure 1. Backscattered electron scanning electron microscope (SEM) picture of two exemplary crystals, which were investigated via wavelength dispersive X-ray spectroscopy (WDX).

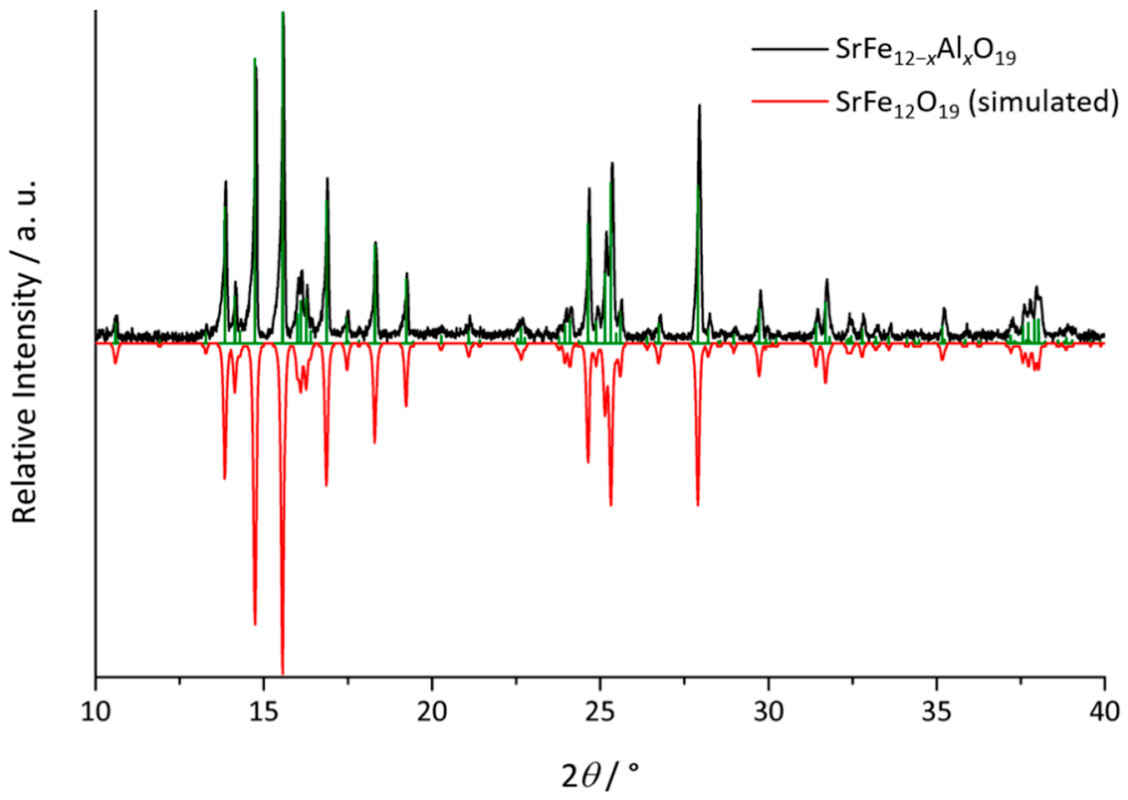

Figure 2. Powder diffraction pattern of $\mathrm{SrFe}_{12-x} \mathrm{Al}_{x} \mathrm{O}_{19}$ (black, up) with marked position of reflexes (green) and simulated pattern of unsubstituted $\mathrm{SrFe}_{12} \mathrm{O}_{19}$ (red, down [14]) measured using Mo- $K_{\alpha}$ radiation.

The crystal structure of the magnetoplumbite $\mathrm{SrFe}_{12} \mathrm{O}_{19}$ is built from close packed oxygen or oxygen-strontium layers which are stacked in both cubic (S-block) and hexagonal sequence (R-block) and can be described as $\left[B A B^{\prime} A B C A C^{\prime} A C\right]_{n}$. One fourth of oxygen anions are replaced by strontium cations in B' and C.' Iron occupies five crystallographically unique sites in the lattice, with three of them being octahedrally, and the remaining two being tetrahedrally and trigonal-bipyramidally coordinated, respectively $[4,14]$. The extended unit cell of the magnetoplumbite structure is depicted in Figure 3 (left), as well as a section of the structure with labelled mixed sites and coordination polyhedra around the cations, where $M=\mathrm{Fe}, \mathrm{Al}$ (right). 
Table 1. Comparison of crystallographic data, refinement parameters and measurement conditions for crystals treated under different conditions.

\begin{tabular}{|c|c|c|c|}
\hline Crystal & 1 & 2 & 3 \\
\hline $\begin{array}{l}\text { Refined composition } \\
\text { Crystal system }\end{array}$ & $\mathrm{SrFe}_{11.2(1)} \mathrm{Al}_{0.8(1)} \mathrm{O}_{19}$ & $\begin{array}{c}\mathrm{SrFe}_{11.2(2)} \mathrm{Al}_{0.8(2)} \mathrm{O}_{19} \\
\text { Hexagonal }\end{array}$ & $\mathrm{SrFe}_{11.0(1)} \mathrm{Al}_{1.0(1)} \mathrm{O}_{19}$ \\
\hline Space group type & & $P 6_{3} / m m c($ No. 194) & \\
\hline$a / \mathrm{pm}$ & $588.37(1)$ & 587.39(1) & 587.41(1) \\
\hline$c / \mathrm{pm}$ & $2304.34(7)$ & $2300.42(6)$ & $2300.62(6)$ \\
\hline Z & 2 & 2 & 2 \\
\hline Density $\rho$ (calculated) $/ \mathrm{g} / \mathrm{cm}^{3}$ & 4.966 & 4.991 & 4.990 \\
\hline Volume $V / 10^{8} \cdot \mathrm{pm}^{3}$ & $6.9084(3)$ & $6.8737(2)$ & $6.8748(2)$ \\
\hline Diffractometer & & $\kappa-\mathrm{CCD}$ (Bruker-Nonius) & \\
\hline Wavelength & & Mo- $K_{\alpha}, \lambda=71.073 \mathrm{pm}$ & \\
\hline Index ranges $h k l$ & $h= \pm 8 ; k= \pm 9 ; l= \pm 36$ & $\begin{array}{c}-8 \leq h \leq 7 ; \mathrm{k}= \pm 9 ;-21 \leq l \\
\leq 36\end{array}$ & $h= \pm 9 ; k= \pm 9 ;-34 \leq l \leq 36$ \\
\hline Measurement range $\left.\theta_{\max }\right|^{\circ}$ & 69.88 & 69.87 & 69.87 \\
\hline$F(000)$ & 978.0 & 978.0 & 978.0 \\
\hline$\mu\left(\mathrm{Mo} \mathrm{K}_{\alpha}\right) / \mathrm{mm}^{-1}$ & 15.18 & 15.26 & 15.25 \\
\hline $\begin{array}{c}\text { Reflections } \\
\text { collected/independent }\end{array}$ & $15718 / 645$ & $14639 / 645$ & $16598 / 645$ \\
\hline$R_{\mathrm{int}} / R_{\sigma}$ & $0.0445 / 0.0151$ & $0.0620 / 0.0193$ & $0.0733 / 0.0225$ \\
\hline$R_{1} / R_{1}$ with $F_{0} \geq 4 \sigma\left(F_{0}\right)$ & $0.0297 / 0.0245$ & $0.0371 / 0.0310$ & $0.0443 / 0.0324$ \\
\hline$w R_{2} / G o o F$ & $0.0576 / 1.090$ & $0.0785 / 1.155$ & $0.0872 / 1.125$ \\
\hline $\begin{array}{l}\text { Largest } \mathrm{e}^{-} \text {difference } \\
\text { peak/hole }\end{array}$ & $0.89 /-0.82$ & $0.85 /-1.49$ & $1.27 /-1.53$ \\
\hline
\end{tabular}

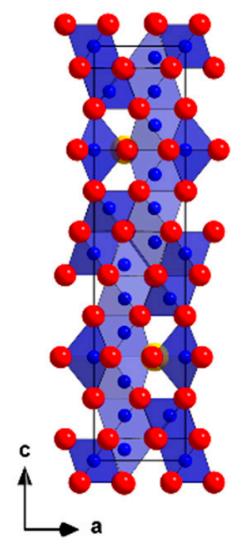

(a)

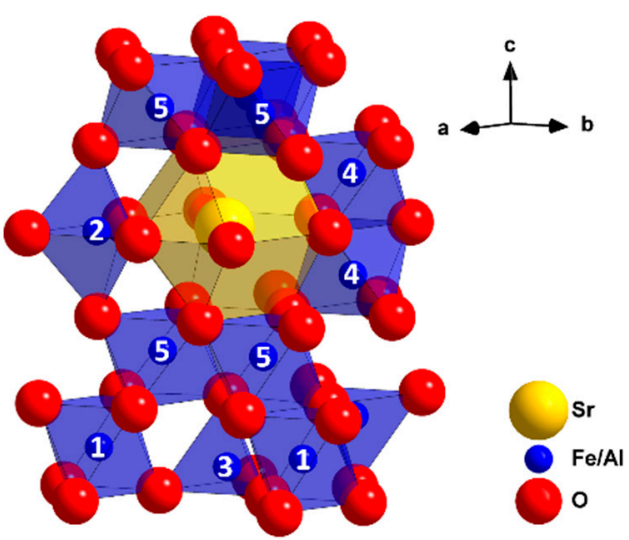

(b)

Figure 3. (a) Unit cell of the product with magnetoplumbite structure, viewed along [010] with polyhedra around $M ;(\mathbf{b})$ A section of the hexagonal structure where iron sites are labelled with numbers 1 (M(1), octahedrally coordinated), 2 ( $M(2)$, trigonal bipyramidally coordinated), $3(M(3)$, tetrahedrally coordinated), 4 and $5(M(4), M(5)$, octahedrally coordinated) and are mixed occupied by both iron and aluminum in different ratios.

The literature states different favored cation sites for $\mathrm{Al}$ in the magnetoplumbite structure. Both Albanese and Choi et al. investigated BaM via Mössbauer spectroscopy in 1995 and 2004 respectively. Examining the quadrupole splitting of $\mathrm{Al}$ substituted barium hexaferrite they found that Al preferably occupies $M(5)$ as well as $M(1)$ and $M(3)$ to a smaller degree $[25,26]$. In an earlier work, Albanese et al. described that occupation of $M(2)$ by $\mathrm{Al}$ in SrM is even less likely [27]. Contrary to this, Awawdeh et al. stated in 2014 that $M(4)$ is preferred, using the same method [28]. Vinnik et al. investigated $\mathrm{Al}$ substituted $\mathrm{BaM}$ using scXRD. According to the refinement, $\mathrm{Al}$ prefers $M(1)$ and then $M(5)$ with smaller amounts on $M(2)$ and $M(4)$. The tetrahedrally coordinated $M(3)$ is not occupied at small Al contents around $x=1$ [16]. In our scXRD refinements on crystals obtained after the initial synthesis, we could confirm the general results of Vinnik. M(3) has little to no Al but we found that the 
majority of $\mathrm{Al}$ is located on $M(5)$. To investigate these reported differences in the occupation, annealing experiments of single crystals were performed. During the investigation via WDX and refinement of scXRD data, it became evident that the $\mathrm{Al}$ distribution on the trivalent metal cation sites and the homogeneity of the received crystals are dependent on the synthesis parameters like annealing time. The asymmetric unit for every unique ion site in the structure as well as the distribution of $\mathrm{Al}$ on the iron sites and the isotropic displacement factors $U_{\text {iso }}$ for a crystal obtained in the initial synthesis are given in Table 2. The same is shown in Table 3 for a crystal annealed in a Pt crucible and in Table 4, for a crystal annealed in a corundum crucible.

Table 2. Wyckoff sites, fractional coordinates in the asymmetric unit, occupational parameters and isotropic displacement factors for every unique ion site of the pristine crystal $1\left(\operatorname{SrFe}_{11.2(1)} \mathrm{Al}_{0.8(1)} \mathrm{O}_{19}\right)$ with $M=\mathrm{Fe}, \mathrm{Al}$ (composition from single crystal X-ray diffraction (scXRD) refinement).

\begin{tabular}{ccccccc}
\hline Atom & Site & $x / a$ & $y / b$ & $z / c$ & Occupation & $U_{\text {iso }} / \mathbf{p m}^{\mathbf{2}}$ \\
\hline $\mathrm{Sr}$ & $2 d$ & $2 / 3$ & $1 / 3$ & $1 / 4$ & 1 & $0.0144(2)$ \\
$M(1)$ & $2 a$ & 0 & 0 & 0 & $88 / 12(1)$ & $0.0070(3)$ \\
$M(2)$ & $2 b$ & 0 & 0 & $1 / 4$ & $92 / 8(2)$ & $0.0138(3)$ \\
$M(3)$ & $4 f$ & $1 / 3$ & $2 / 3$ & $0.02729(3)$ & $96 / 4(1)$ & $0.0065(2)$ \\
$M(4)$ & $4 f$ & $1 / 3$ & $2 / 3$ & $0.19075(3)$ & $93 / 7(1)$ & $0.0070(2)$ \\
$M(5)$ & $12 k$ & $0.33750(8)$ & $x / 2$ & $0.10914(2)$ & $93 / 6(1)$ & $0.0071(2)$ \\
$\mathrm{O}(1)$ & $4 e$ & 0 & 0 & $0.1511(2)$ & 1 & $0.0087(6)$ \\
$\mathrm{O}(2)$ & $4 f$ & $2 / 3$ & $1 / 3$ & $0.0553(2)$ & 1 & $0.0099(6)$ \\
$\mathrm{O}(3)$ & $6 h$ & $0.1816(3)$ & $2 x$ & $1 / 4$ & 1 & $0.0119(6)$ \\
$\mathrm{O}(4)$ & $12 k$ & 0.15616 & $2 x$ & $0.05231(8)$ & 1 & $0.0085(4)$ \\
$\mathrm{O}(5)$ & $12 k$ & $0.546(2)$ & $\bar{x}$ & $0.15080(8)$ & 1 & $0.0097(4)$ \\
\hline
\end{tabular}

Table 3. Wyckoff sites, fractional coordinates in the asymmetric unit, occupational parameters and isotropic displacement factors for every unique ion site of crystal 2 after annealing in a platinum crucible $\left(\mathrm{SrFe}_{11.2(2)} \mathrm{Al}_{0.8(2)} \mathrm{O}_{19}\right)$ with $M=\mathrm{Fe}, \mathrm{Al}$ (composition from scXRD refinement).

\begin{tabular}{ccccccc}
\hline Atom & Site & $x / a$ & $y / b$ & $z / c$ & Occupation & $\boldsymbol{U}_{\text {iso }} / \mathbf{p m}^{\mathbf{2}}$ \\
\hline $\mathrm{Sr}$ & $2 d$ & $2 / 3$ & $1 / 3$ & $1 / 4$ & 1 & $0.0152(3)$ \\
$M(1)$ & $2 a$ & 0 & 0 & 0 & $78 / 22(2)$ & $0.0070(4)$ \\
$M(2)$ & $2 b$ & 0 & 0 & $1 / 4$ & $93 / 7(2)$ & $0.0151(4)$ \\
$\mathrm{Fe}(3)$ & $4 f$ & $1 / 3$ & $2 / 3$ & $0.02729(3)$ & 1 & $0.0071(3)$ \\
$M(4)$ & $4 f$ & $1 / 3$ & $2 / 3$ & $0.19056(4)$ & $95 / 5(2)$ & $0.0076(3)$ \\
$M(5)$ & $12 k$ & $0.33725(9)$ & $x / 2$ & $0.10901(2)$ & $94 / 6(1)$ & $0.0077(2)$ \\
$\mathrm{O}(1)$ & $4 e$ & 0 & 0 & $0.1507(2)$ & 1 & $0.0082(7)$ \\
$\mathrm{O}(2)$ & $4 f$ & $2 / 3$ & $1 / 3$ & $0.0558(2)$ & 1 & $0.0092(8)$ \\
$\mathrm{O}(3)$ & $6 h$ & $0.1816(4)$ & $2 x$ & $1 / 4$ & 1 & $0.0128(7)$ \\
$\mathrm{O}(4)$ & $12 k$ & $0.1558(3)$ & $2 x$ & $0.0521(1)$ & 1 & $0.0084(5)$ \\
$\mathrm{O}(5)$ & $12 k$ & $0.5043(3)$ & $\bar{x}$ & $0.1502(1)$ & 1 & $0.0091(4)$ \\
\hline
\end{tabular}

After annealing in a platinum or a corundum crucible, redistribution was indeed observed in occupation of the mixed sites. As can be taken from Tables $2-4$, the coordinates of the ions did not change significantly and the $U_{\text {iso }}$ are similar before and after the annealing experiments. The aluminum distribution however did change. Upon annealing, its content is doubled on the octahedrally coordinated site $M(1)$ whereas it is significantly reduced on $M(3)$, while the refined substitution levels are similar. The contents on $M(2)$ and $M(4)$ in the R-block are affected to only a small degree. Noteworthy, upon annealing, the unit cell parameters shrinks by about $0.2 \%$ leading to a density increase of $0.5 \%$ due to atomic redistribution. 
Table 4. Wyckoff sites, fractional coordinates in the asymmetric unit, occupational parameters and isotropic displacement factors for every unique ion site of crystal 3 after annealing in an aluminum oxide crucible ( $\mathrm{SrFe}_{11.0(1)} \mathrm{Al}_{1.0(1)} \mathrm{O}_{19}$ ) with $\mathrm{M}=\mathrm{Fe}, \mathrm{Al}$ (composition from scXRD refinement).

\begin{tabular}{ccccccc}
\hline Atom & Site & $x / \boldsymbol{a}$ & $\boldsymbol{y} / \boldsymbol{b}$ & $z / \boldsymbol{c}$ & Occupation & $\boldsymbol{U}_{\text {iso }} / \mathbf{p m}^{\mathbf{2}}$ \\
\hline $\mathrm{Sr}$ & $2 d$ & $2 / 3$ & $1 / 3$ & $1 / 4$ & 1 & $0.0167(3)$ \\
$M(1)$ & $2 a$ & 0 & 0 & 0 & $76 / 24(2)$ & $0.0077(4)$ \\
$M(2)$ & $2 b$ & 0 & 0 & $1 / 4$ & $92 / 8(2)$ & $0.0159(5)$ \\
$M(3)$ & $4 f$ & $1 / 3$ & $2 / 3$ & $0.02731(4)$ & $98 / 2(1)$ & $0.0079(3)$ \\
$M(4)$ & $4 f$ & $1 / 3$ & $2 / 3$ & $0.19058(4)$ & $94 / 6(1)$ & $0.0083(3)$ \\
$M(5)$ & $12 k$ & $0.33715(9)$ & $x / 2$ & $0.10902(2)$ & $92 / 8(1)$ & $0.0083(2)$ \\
$\mathrm{O}(1)$ & $4 e$ & 0 & 0 & $0.1508(2)$ & 1 & $0.0095(8)$ \\
$\mathrm{O}(2)$ & $4 f$ & $2 / 3$ & $1 / 3$ & $0.0555(2)$ & 1 & $0.0097(9)$ \\
$\mathrm{O}(3)$ & $6 h$ & $0.1817(4)$ & $2 x$ & $1 / 4$ & 1 & $0.0129(8)$ \\
$\mathrm{O}(4)$ & $12 k$ & $0.1553(3)$ & $2 x$ & $0.0521(2)$ & 1 & $0.0099(5)$ \\
$\mathrm{O}(5)$ & $12 k$ & $0.5040(3)$ & $\bar{x}$ & $0.1502(2)$ & 1 & $0.0105(5)$ \\
\hline
\end{tabular}

According to the refinement, annealing in a corundum crucible slightly increases the $\mathrm{Al}$ content in the structure. WDX experiments yielded additional information about the homogeneity and $\mathrm{Al}$ content of the material. Crystals with edge lengths up to $1 \mathrm{~mm}$, taken from the initial synthesis, after annealing in a platinum crucible or in a corundum crucible, were examined at six to ten locations on the crystal surface. The average $\mathrm{Al}$ contents in at.- $\%$ for the three samples are shown in Table 5. The errors represent the highest discrepancy of a single value to the average. The high errors of the former two samples indicate that, although the $\mathrm{Al}$ distribution on the different metal ion sites changes, annealing alone will not suffice to homogenize the material. However, it is possible that additional $\mathrm{Al}$ ions can diffuse into the hexaferrite when heated while in contact with the corundum crucible and a homogeneous distribution can be achieved in this way. This can be derived from the lower error of the average content after annealing in the corundum crucible. It can also be seen that the relative content of $\mathrm{Al}$ increases in comparison to that obtained directly after the initial synthesis and annealing, which both took place in a platinum crucible. This strengthens the presumption that $\mathrm{Al}$ diffuses into the crystal from the crucible material. This is very probable as corundum and hematite crystallize isotypic [29].

Table 5. Average aluminum contents of samples from the initial synthesis and annealed samples in at.-\%. Shown errors represent the highest discrepancy between a single value and the average.

\begin{tabular}{lc}
\hline \multicolumn{1}{c}{ Sample } & Average Aluminum Content/at.-\% \\
\hline Crystal 1 from initial synthesis & $1.7 \pm 0.2$ \\
Crystal 2 from annealing in platinum crucible & $2.0 \pm 0.5$ \\
Crystal 3 from annealing in corundum crucible & $2.15 \pm 0.08$ \\
\hline
\end{tabular}

\subsection{Magnetism}

Magnetic measurements were performed on both powdered samples and larger crystals. The magnetic field was applied along the $c$ axis for the latter. In Figures 4 and 5, the magnetic moment is plotted against the magnetic field strength to investigate the magnetic hysteresis. The former figure shows a curve for a powder (red) and a crystal (black). It can be seen that the hysteresis of the crystal is much steeper than the hysteresis of the powder, which is desired in a hard magnetic material but widens considerably in a powdered sample. 


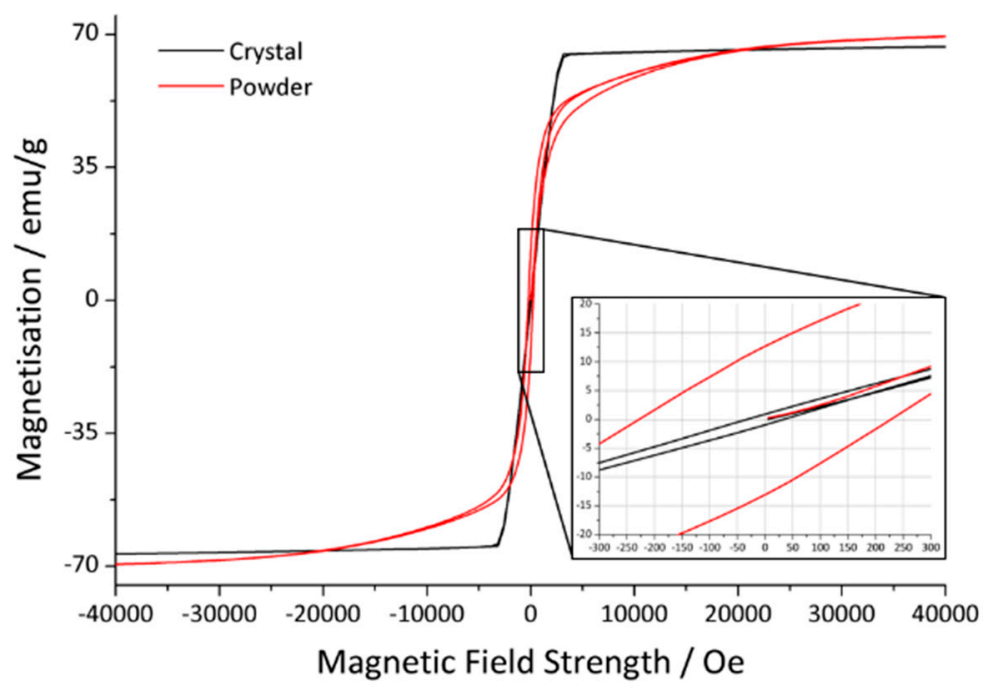

Figure 4. Hysteresis curve of a crystal (black) and a powder sample (red). The zoomed in part emphasizes the coercivity and the remanence.

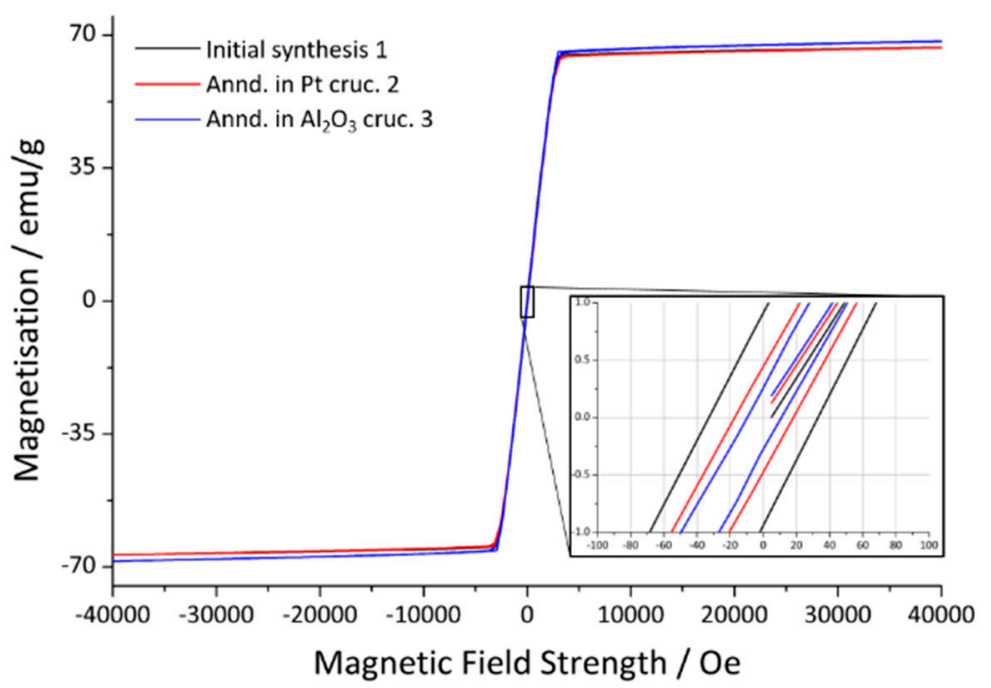

Figure 5. Hysteresis curves of a crystal sample from the initial synthesis (black), after annealing in a platinum crucible (red) and corundum crucible (blue) with the magnetic field applied parallel to the $c$ axis. The area around the origin is magnified to show the coercivity and remanence.

The magnetic hysteresis loops for three crystals after different degrees of annealing, as described in Section 2, are shown in Figure 5. The magnetic data derived from the curves, the saturation magnetization $M_{\mathrm{s}}$, remanence $M_{\mathrm{r}}$ and coercivity $H_{\mathrm{c}}$, are summarized in Table 6 . It is obvious that the hysteresis shape and $M_{\mathrm{S}}$ do not vary much, whereas $M_{\mathrm{r}}$ and $H_{\mathrm{c}}$ decrease significantly after annealing.

Table 6. Saturation magnetization $M_{\mathrm{S}}$, remanence $M_{\mathrm{r}}$ and coercivity $H_{\mathrm{c}}$ of four investigated samples.

\begin{tabular}{lccc}
\hline \multicolumn{1}{c}{ Sample } & $\boldsymbol{M}_{\mathbf{s}} / \mathbf{e m u} / \mathbf{g}$ & $\boldsymbol{M}_{\mathbf{r}} / \mathbf{e m u} / \mathbf{g}$ & $\boldsymbol{H}_{\mathrm{c}} / \mathbf{O e}$ \\
\hline Powder & 71.1 & 12.8 & 226.1 \\
Crystal 1 from initial synthesis & 67.8 & 0.9 & 33.0 \\
Crystal 2 from annealing in platinum crucible & 68.1 & 0.4 & 18.1 \\
Crystal 3 from annealing in corundum crucible & 69.9 & 0.3 & 10.9 \\
\hline
\end{tabular}

According to the literature, both the saturation magnetization and remanence decrease significantly and the coercivity increases with higher substitution rates [26,28,30,31]. El-Sayed et al. report a drop 
of $M_{\mathrm{S}}$ from $61.2 \mathrm{emu} / \mathrm{g}$ to $49.7 \mathrm{emu} / \mathrm{g}, M_{\mathrm{r}}$ from $31.5 \mathrm{emu} / \mathrm{g}$ to $25.8 \mathrm{emu} / \mathrm{g}$ and an increase in $H_{\mathrm{c}}$ from $1.66 \mathrm{kOe}$ to $1.77 \mathrm{kOe}$ [30]. However, those values highly depend on the synthesis temperature and particle size $[30,31]$. The relatively low values presented here are to be expected as plates in millimeter scale were investigated. The critical domain size is exceeded, which results in lower overall values [31]. A drop of $M_{\mathrm{r}}$ was indeed observed after annealing concomitant to a decreasing $H_{\mathrm{C}}$ (see Table 6).

\section{Conclusions}

Single crystals of aluminum substituted strontium hexaferrite, $\mathrm{SrFe}_{12-x} \mathrm{Al}_{x} \mathrm{O}_{19}$, up to several millimeters in length, were grown from a sodium oxide based flux in a platinum crucible. ScXRD measurements show that the aluminum distribution over the five available sites depends on the duration of the annealing. The WDX measurements show that previously inhomogeneous $\mathrm{Al}$ substituted hexaferrites can be homogenized by annealing in a corundum crucible, while slightly increasing the degree of substitution. These results offer a direct explanation for various contradicting reports on metal ion distributions in hexaferrites. The shape of the magnetic hysteresis loop and the $M_{\mathrm{S}}$ value are hardly affected by the annealing but $M_{\mathrm{r}}$ and $H_{\mathrm{c}}$ decrease when annealing after the initial synthesis. The powder sample shows a broader hysteresis curve.

Author Contributions: Conceptualization, D.A.V. and R.N.; validation, M.H.; formal analysis, M.H.; investigation, M.H. and D.A.V.; writing—original draft preparation, M.H.; writing-review and editing, R.N.; visualization, M.H.; supervision, R.N.; project administration, D.A.V. and R.N.; funding acquisition, D.A.V. All authors have read and agreed to the published version of the manuscript.

Funding: In SUSU the single crystal growth part of the presented work was partially supported by the Government of the Russian Federation (Act 211, contract № 02.A03.21.0011) and by the Russian Foundation for Basic Research (№ 18-32-00663).

Conflicts of Interest: The authors declare no conflict of interest.

\section{References}

1. Pullar, R.C. Hexagonal ferrites: A review of the synthesis, properties and applications of hexaferrite ceramics. Prog. Mater. Sci. 2012, 57, 1191-1334. [CrossRef]

2. Bragg, W.H. The Structure of Magnetite and the Spinels. Nature 1915, 95, 561. [CrossRef]

3. Bragg, W.H. XXX. The Structure of the Spinel Group of Crystals. Philos. Mag. 1915, 30, 305-315. [CrossRef]

4. Obradors, X.; Collomb, A.; Pernet, M. X-Ray Analysis of the Structural and Dynamic Properties of $\mathrm{BaFe}_{12} \mathrm{O}_{19}$ Hexagonal Ferrite at Room Temperature. J. Solid State Chem. 1985, 56, 171-181. [CrossRef]

5. Morisako, A.; Matsumoto, M.; Naoe, M. Ba-ferrite thin film rigid disk for high density perpendicular magnetic recording. IEEE Trans. Magn. 1986, 22, 1146-1148. [CrossRef]

6. Ferrites - Physical Properties of Ferrimagnetic Oxides in Relation to their Technical Applications; Smit, J.; Wijn, H.P.J. (Eds.) Philips' Technical Library: Eindhoven, The Netherlands, 1959.

7. Primc, D.; Makovec, D.; Lisjak, D.; Drofenik, M. Hydrothermal synthesis of ultrafine barium hexaferrite nanoparticles and the preparation of their stable suspensions. Nanotechnology 2009, 20, 315605-315613. [CrossRef]

8. Drofenik, M.; Kristl, M.; Žnidaršič, A.; Hanžel, D.; Lisjak, D. Hydrothermal Synthesis of Ba-Hexaferrite Nanoparticles. J. Am. Ceram. Soc. 2007, 90, 2057-2061. [CrossRef]

9. Sui, X.; Scherge, M.; Kryder, M.H.; Snyder, J.E.; Harris, V.G.; Koon, N.C. Barium ferrite thin-film recording media. J. Magn. Magn. Mater. 1996, 155, 132-139. [CrossRef]

10. Barb, D.; Diamandescu, L.; Rusi, A.; Tărăbăsanu-Mihăilă, D.; Morariu, M.; Teodorescu, V. Preparation of barium hexaferrite by a hydrothermal method: Structure and magnetic properties. J. Mater. Sci. 1986, 21, 1118-1122. [CrossRef]

11. Mali, A.; Ataie, A. Structural characterization of nano-crystalline $\mathrm{BaFe}_{12} \mathrm{O}_{19}$ powders synthesized by sol-gel combustion route. Scr. Mater. 2005, 53, 1065-1070. [CrossRef]

12. Sürig, C.; Hempel, K.A.; Bonnenberg, D. Hexaferrite particles prepared by sol-gel technique. IEEE Trans. Magn. 1994, 30, 4092-4094. [CrossRef] 
13. Vinnik, D.A.; Tarasova, A.Y.; Zherebtsov, D.A.; Gudkova, S.A.; Galimov, D.M.; Zhivulin, V.E.; Trofimov, E.A.; Nemrava, S.; Perov, N.S.; Isaenko, L.I.; et al. Magnetic and Structural Properties of Barium Hexaferrite $\mathrm{BaFe}_{12} \mathrm{O}_{19}$ from Various Growth Techniques. Materials 2017, 10. [CrossRef]

14. Obradors, X.; Solans, X.; Collomb, A.; Samaras, D.; Rodriguez, J.; Pernet, M.; Font-Altaba, M. Crystal Structure of Strontium Hexaferrite $\mathrm{SrFe}_{12} \mathrm{O}_{19}$. J. Solid State Chem. 1988, 72, 218-224. [CrossRef]

15. Blix, R. On the chemical composition of the magnetoplumbite: (With a new analysis.). Geol. Foeren. Stockholm Foerh. 1937, 59, 300-302. [CrossRef]

16. Vinnik, D.A.; Zherebtsov, D.A.; Mashkovtseva, L.S.; Nemrava, S.; Bischoff, M.; Perov, N.S.; Semisalova, A.S.; Krivtsov, I.V.; Isaenko, L.I.; Mikhailov, G.G.; et al. Growth, structural and magnetic characterization of Al-substituted barium hexaferrite single crystals. J. Alloys Compd. 2014, 615, 1043-1046. [CrossRef]

17. Shlyk, L.; Vinnik, D.A.; Zherebtsov, D.A.; Hu, Z.; Kuo, C.-Y.; Chang, C.-F.; Lin, H.-J.; Yang, L.-Y.; Semisalova, A.S.; Perov, N.S.; et al. Single crystal growth, structural characteristics and magnetic properties of chromium substituted $M$-type ferrites. Solid State Sci. 2015, 50, 23-31. [CrossRef]

18. Wang, C.-A.; Lu, H.; Huang, Z.; Xie, H. Enhanced anti-deliquescent property and ultralow thermal conductivity of magnetoplumbite-type $\mathrm{LnMeAl}_{11} \mathrm{O}_{19}$ materials for thermal barrier coating. J. Am. Ceram. Soc. 2018, 101, 1095-1104. [CrossRef]

19. Vinnik, D.A.; Zherebtsov, D.A.; Mashkovtseva, L.S.; Nemrava, S.; Yakushechkina, A.K.; Semisalova, A.S.; Gudkova, S.A.; Anikeev, A.N.; Perov, N.S.; Isaenko, L.I.; et al. Tungsten substituted $\mathrm{BaFe}_{12} \mathrm{O}_{19}$ single crystal growth and characterization. Mater. Chem. Phys. 2015, 155, 99-103. [CrossRef]

20. Vinnik, D.A.; Zherebtsov, D.A.; Mashkovtseva, L.S.; Nemrava, S.; Perov, N.S.; Semisalova, A.S.; Krivtsov, I.V.; Isaenko, L.I.; Mikhailov, G.G.; Niewa, R. Ti-Substituted $\mathrm{BaFe}_{12} \mathrm{O}_{19}$ Single Crystal Growth and Characterization. Cryst. Growth Des. 2014, 14, 5834-5839. [CrossRef]

21. Vinnik, D.A.; Tarasova, A.Y.; Zherebtsov, D.A.; Mashkovtseva, L.S.; Gudkova, S.A.; Nemrava, S.; Yakushechkina, A.K.; Semisalova, A.S.; Isaenko, L.I.; Niewa, R. Cu-substituted barium hexaferrite crystal growth and characterization. Ceram. Int. 2015, 41, 9172-9176. [CrossRef]

22. Nemrava, S.; Vinnik, D.A.; Hu, Z.; Valldor, M.; Kuo, C.-Y.; Zherebtsov, D.A.; Gudkova, S.A.; Chen, C.-T.; Tjeng, L.H.; Niewa, R. Three Oxidation States of Manganese in the Barium Hexaferrite $\mathrm{BaFe}_{12-x} \mathrm{Mn}_{x} \mathrm{O} 19$. Inorg. Chem. 2017, 56, 3861-3866. [CrossRef] [PubMed]

23. Moon, K.W.; Jeon, K.W.; Kim, J. Synthesis and Magnetic Properties of $\mathrm{BaFe}_{12-\mathrm{x}} \mathrm{Al}_{\mathrm{x}} \mathrm{O}_{19}$ Nanopowders. IEEE Trans. Magn. 2009, 45, 4405-4408. [CrossRef]

24. Gambino, R.J.; Leonhard, F. Growth of Barium Ferrite Single Crystals. J. Am. Ceram. Soc. 1961, 44, $221-224$. [CrossRef]

25. Albanese, G. Mössbauer investigation of aluminium substituted barium hexaferrite in the paramagnetic state. J. Magn. Magn. Mater. 1995, 147, 421-426. [CrossRef]

26. Choi, D.H.; An, S.Y.; Lee, S.W.; Shim, I.-B.; Kim, C.S. Site occupancy and anisotropy distribution of Al substituted Ba-ferrite with high coercivity. Phys. Stat. Solidi B 2004, 241, 1736-1739. [CrossRef]

27. Albanese, G.; Carbucicchio, M.; Deriu, A. Substitution of $\mathrm{Fe}^{3+}$ by $\mathrm{Al}^{3+}$ in the Trigonal Sites of $M$-Type Hexagonal Ferrites. Nuovo Cimento 1973, 15B, 147-158. [CrossRef]

28. Awawdeh, M.; Bsoul, I.; Mahmood, S.H. Magnetic properties and Mössbauer spectroscopy on $\mathrm{Ga}, \mathrm{Al}$ and $\mathrm{Cr}$ substituted hexaferrites. J. Alloys Compd. 2014, 585, 465-473. [CrossRef]

29. Pauling, L.; Hendricks, S.B. The crystal structures of hematite and corundum. J. Am. Chem. Soc. 1925, 47, 781-790. [CrossRef]

30. El-Sayed, S.M.; Meaz, T.M.; Amer, M.A.; El Shersaby, H.A. Magnetic behavior and dielectric properties of aluminum substituted M-type barium hexaferrite. Physica B 2013, 426, 137-143. [CrossRef]

31. Iqbal, M.J.; Ashiq, M.N.; Hernandez-Gomez, P.; Munoz, J.M. Synthesis, physical, magnetic and electrical properties of Al-Ga substituted co-precipitated nanocrystalline strontium hexaferrite. J. Magn. Magn. Mater. 2008, 320, 881-886. [CrossRef]

(C) 2020 by the authors. Licensee MDPI, Basel, Switzerland. This article is an open access article distributed under the terms and conditions of the Creative Commons Attribution (CC BY) license (http://creativecommons.org/licenses/by/4.0/). 